\title{
Effect of the mean stress and the third invariant in the fatigue life assuming random loading
}

\author{
Lucival Malcher * and Rodrigue Desmorat ${ }^{\dagger}$ \\ *University of Brasília, Faculty of Technology, Department of Mechanical Engineering. Campus \\ Darcy Ribeiro, Brasília, Distrito Federal, Brazil \\ e-mail: malcher@unb.br \\ ${ }^{\dagger}$ Université Paris-Saclay, ENS Paris-Saclay, CNRS, LMT - Laboratoire de Mécanique et \\ Technologie, 94235, Cachan, France \\ e-mail: rodrigue.desmorat@ens-cachan.fr
}

\begin{abstract}
This work seeks to present a way to calculate the mean stress under conditions of random loading, as well as to show the effect of the third invariant of the deviatoric stress tensor in the prediction of fatigue life, under low and high number of cycles. Thus, it is proposed to use the so-called "exponential moving average scheme" to determine the mean stress, as well as a modification of the Gao yield criterion, to couple the effect of the mean value and use the third invariant to calculate the equivalent stress. The fatigue life is calculated based on incremental damage proposed by Lemaitre and modified by Malcher \& Mamiya. The proposed approach shows that the reduction of the mean stress transient strongly affects the calculation of fatigue life. In addition, the calculation of the equivalent stress, taking into account the third invariant, mainly under shear loading conditions, also has a great influence on the life calculation. Finally, the proposal shows that incremental damage is a valid alternative for calculating fatigue life under random loading conditions
\end{abstract}
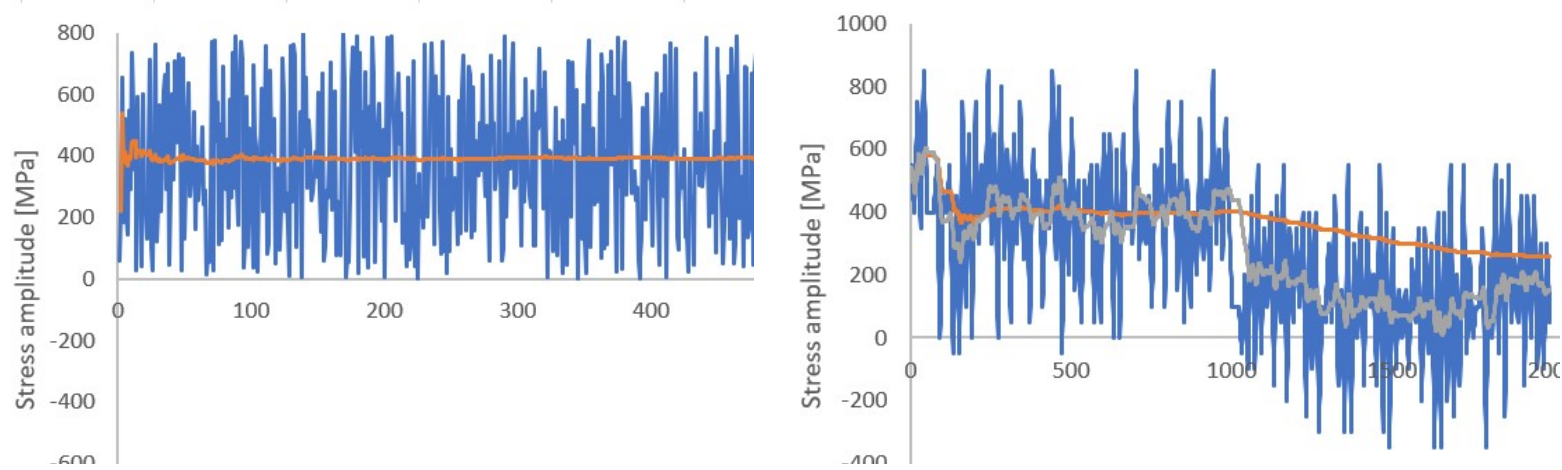

Figure 1 - Mean stress value in random loading.

\section{REFERENCES}

[1] R. Desmorat, L. Angrand, P. Gaborit, M. Kaminski, C. Rakotoarisoa. On the introduction of a mean stress in kinetic damage evolution lawsfor fatigue, 2015. International Journal of Fatigue.

[2] L. Malcher, E.N. Mamiya. An improved damage evolution law based on continuumdamage mechanics and its dependence on both stress triaxialityand the third invariant, 2014. International Journal of Plasticity. 